\title{
Role and uptake of human papillomavirus vaccine in adolescent health in the United States
}

This article was published in the following Dove Press journal:

Adolescent Health, Medicine and Therapeutics

5 August 20II

Number of times this article has been viewed

\section{Staci L Sudenga \\ Kathryn E Royse \\ Sadeep Shrestha}

Department of Epidemiology, School of Public Health, University of Alabama at Birmingham, Birmingham, AL, USA
Correspondence: Sadeep Shrestha

Department of Epidemiology, University of Alabama at Birmingham, I 665

University Blvd, RPHB 217 L Birmingham, AL 35294-0022, USA

Tel +l 2059346459

Fax +I 2059753329

Email sshrestha@uab.edu
Abstract: Both the prophylactic human papillomavirus (HPV) vaccines, Gardasil ${ }^{\circledR}$ and Cervarix $^{\circledR}$, are licensed for the prevention of cervical cancer in females, and Gardasil is also licensed for the prevention of genital warts and anal cancer in both males and females. This review focuses on the uptake of these vaccines in adolescent males and females in the USA and the barriers associated with vaccine initiation and completion. In the USA in 2009, approximately $44.3 \%$ of adolescent females aged 13-17 years had received at least one dose of the HPV vaccine, but only $26.7 \%$ had received all three doses. In general, the Northeast and Midwest regions of the USA have the highest rates of HPV vaccine initiation in adolescent females, while the Southeast has the lowest rates of vaccine initiation. Uptake of the first dose of the HPV vaccine in adolescent females did not vary by race/ethnicity; however, completion of all three doses is lower among African Americans (23.1\%) and Latinos (23.4\%) compared with Caucasians $(29.3 \%)$. At present, vaccination rates among adolescent females are lower than expected, and thus vaccine models suggest that it is more cost-effective to vaccinate both adolescent males and females. Current guidelines for HPV vaccination in adolescent males is recommended only for "permissive use," which leaves this population out of routine vaccination for HPV. The uptake of the vaccine is challenged by the high cost, feasibility, and logistics of three-dose deliveries. The biggest impact on acceptability of the vaccine is by adolescents, physicians, parents, and the community. Future efforts need to focus on HPV vaccine education among adolescents and decreasing the barriers associated with poor vaccine uptake and completion in adolescents before their sexual debut, but Papanicolau screening should remain routine among adults and those already infected until a therapeutic vaccine can be developed.

Keywords: human papillomavirus, vaccine uptake, adolescent health

\section{Introduction}

Human papillomavirus (HPV) is one of the most common causes of sexually transmitted infections (STIs) in both men and women worldwide, including the USA. ${ }^{1}$ Exposure to HPV is common among adolescents aged 13-19 years soon after initiation of intercourse. ${ }^{2,3}$ Studies from a cohort of 19-year-old college females have shown that the cumulative incidences of HPV infection after a 24-month period are similar between virgins who become sexually active and nonvirgins, at $38.8 \%$ and $38.9 \%$, respectively. ${ }^{3}$ In the USA, $24 \%$ of adolescents are sexually active by 15 years, $40 \%$ by 16 years, and $70 \%$ by 18 years. ${ }^{4}$ Number of sexual partners is a major risk factor for HPV acquisition, with $5.7 \%$ and $20.2 \%$ of ninth and twelfth graders, respectively, have had more than four sexual partners. ${ }^{5}$ Of the estimated 20 million persons infected with HPV in the USA, about half are aged 15-24 years; another 6.2 million new cases 
(4.6 million aged 15-24 years) are diagnosed annually. ${ }^{6}$ The rate of subclinical HPV infection is much higher in adolescents $(12 \%-56 \%)^{7-10}$ compared with older women $(2 \%-7 \%),{ }^{6,11}$ with cumulative prevalence rates as high as $82 \%$ in specific subpopulations. ${ }^{12}$ While adolescents have a much lower incidence of cervical or other HPV-related cancers, they are still affected by HPV-related sequelae, like genital warts, which are estimated to effect $3 \%$ of sexually active adolescents. ${ }^{13}$ The importance of the two prophylactic vaccines, currently approved and available, is paramount. However, barriers to uptake exist, and this review focuses on these issues, in the context of the USA.

Long-term persistence of HPV is the key factor in the development of $5 \%$ of all human cancers. ${ }^{14}$ Epidemiological and virological data demonstrate that oncogenic HPVs are the primary (and necessary) causal agents of cervical cancer. ${ }^{15,16}$ HPV-DNA is present in $99.7 \%$ of all cervical carcinomas, and HPV types 16, 18, 45, and 31 are the most predominant. ${ }^{17-19}$ Both of the currently available vaccines contain the two most common HPV types 16 and 18. HPV infection is associated with other cancers besides cervical cancer, as evidenced by the incidence and mortality rates shown in Table 1 . HPV infection is attributable to $35 \%$ of oropharynx, $25 \%$ of oral cavity, $40 \%$ of penile, $90 \%$ of anal, $40 \%$ of vulval, $40 \%$ of vaginal, and $99.9 \%$ of cervical cancers, and oncogenic HPV types $16 / 18$ are responsible for $89 \%, 98 \%, 63 \%, 92 \%, 80 \%$, $80 \%$, and $70 \%$ of all these cancers, respectively (Figure 1 ). ${ }^{20}$ However, there are other HPV types, some also considered oncogenic, not covered by the vaccines that also might contribute to these cancers. Likewise, infection with "benign" or low-risk HPVs that cause genital warts have a life-time acquisition risk of $10 \%$ in the USA and a worldwide prevalence of $0.6 \%-3.0 \%$, which also presents major morbidity and economic cost. ${ }^{21,22}$

Although HPV-related cancers generally occur in older women, and not in adolescents (Table 1), considering the

Table I New cases of HPV-related major cancers in the USA and worldwide ${ }^{42,100,101}$

\begin{tabular}{lccc}
\hline & $\begin{array}{l}\text { Percentage } \\
\text { of all cancers } \\
\text { caused by HPV }\end{array}$ & $\begin{array}{l}\text { New cases per year } \\
\text { USA/worldwide }\end{array}$ & $\begin{array}{l}\text { Median age } \\
\text { of diagnosis } \\
\text { (years) }\end{array}$ \\
\hline Cervix & 3.18 & $12,280 / 53,000$ & 47 \\
Vaginal & 0.12 & $2300 / 13,200$ & 69 \\
Vulval & 0.12 & $3900 / 26,800$ & 70 \\
Anal & 0.23 & $5260 / 99,000$ & 62 \\
Penal & 0.06 & $1250 / 21,100$ & 57 \\
Oral cavity & 0.07 & $10,840 / 183,100$ & 67 \\
Oropharynx & 0.05 & $12,660 / 27,700$ & 64 \\
\hline Abbrevian
\end{tabular}

Abbreviation: HPV, human papillomavirus.

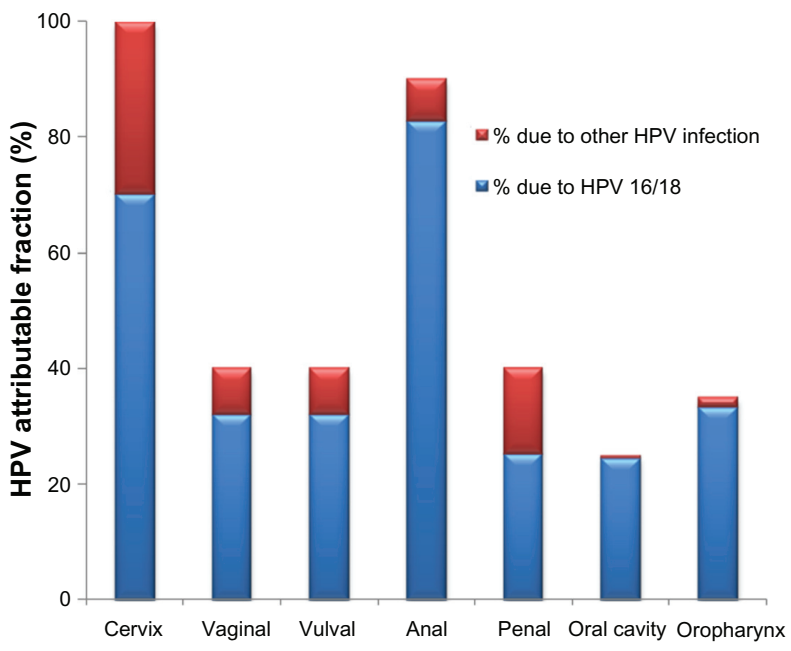

Figure I Major cancers attributable to HPV infection. Seven cancers are associated with HPV infection, total attributable risk to any HPV infection is shown with blue color referring to HPV types 16 and 18 and the remaining due to other HPV infection (in red).

Note: Based on data excerpted from Parkin et al. ${ }^{97}$

Abbreviation: HPV, human papillomavirus.

HPV lifecycle and its attributable fraction to various cancers, any strategy to prevent HPV infection as early as possible seems a major public health priority. HPV-associated cancers and genital warts are potentially preventable by vaccination with the HPV vaccine, which has been shown to be efficacious, specifically against the most oncogenic HPV types 16 and 18. This review summarizes some of the current knowledge about the role and uptake of the HPV vaccine in adolescent health in the USA.

\section{HPV vaccine}

On June 8, 2006, the Food and Drug Administration (FDA) approved the three-dose quadrivalent (HPV types 6, 11, 16, and 18) HPV vaccine, Gardasil ${ }^{\circledR}$ (Merck Sharp and Dohme, Whitehouse Station, NJ), also known as HPV4, ${ }^{23}$ and on October 16, 2009, the FDA approved the threedose bivalent (HPV types 16 and 18 ) vaccine, Cervarix ${ }^{\circledR}$ (GlaxoSmithKline, Research Triangle Park, NJ), also known as HPV2. ${ }^{24}$ Gardasil is currently approved in more than 123 countries and Cervarix in 66 countries. ${ }^{25}$ Both vaccines are prophylactic and contain virus-like particles of HPV types that stimulate type-specific neutralizing antibodies. Both HPV vaccines have demonstrated better than $90 \%$ efficacy (Table 2) in reducing the risk of precancerous lesions (cervical intraepithelial neoplasia grade 2 and 3, CIN2 and CIN3, respectively) and adenocarcinoma in situ from the targeted HPV vaccine types for up to 5 years. ${ }^{26-28}$ Gardasil was also shown to be highly efficacious for preventing genital warts in males aged 16-26 years and was licensed by the FDA 


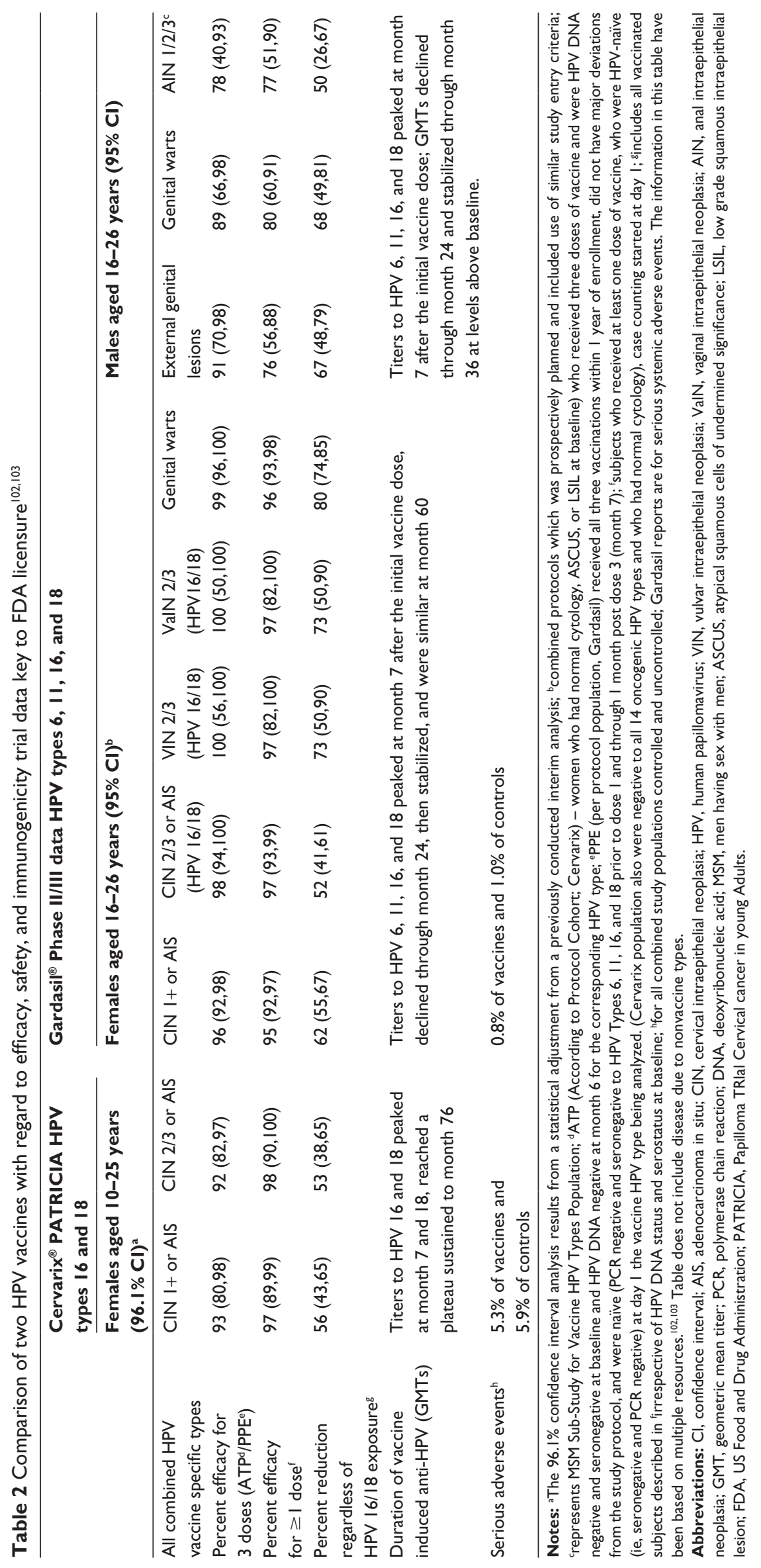


in 2009, and Gardasil was also licensed by the FDA in 2010 for the prevention of precancerous anal lesions and cancer in males and females aged 16-26 years. ${ }^{29,30}$ Additional vaccine characteristics and clinical trial data key for licensure by the FDA are described and compared briefly in Table 2.

Initially, vaccine-induced immune titers to the specific HPV types are much higher (10-104 times) than seen after natural infection. However, the minimum anti-HPV titer that confers protective efficacy has not been determined. Immunogenicity data based on geometric mean titers indicate a significantly higher antibody response in younger adolescents (9-15 years) compared with older women (16-26 years). ${ }^{31,32}$ Antibody levels to type-specific HPV generally peak at 1 month after the third dose, followed by a decline (of one log) until month 18 following vaccination, after which it stabilizes and remains as high as or higher still than that seen after natural infection, but little is known about the long-term duration of these antibody titers. Clinical trial populations have demonstrated sustained immunogenicity for up to 6.4 years following vaccination, ${ }^{28}$ but an ideal prophylactic vaccine should provide protection for 10-15 years to protect 11-12-year-old adolescents during the period when they are most likely to be exposed and susceptible to HPV infection. ${ }^{33}$ Additional data on duration of protection and outcomes will be available from ongoing prospective studies, such as the GARDASIL Vaccine Impact in Population Study (VIP), monitored through vaccine registries in women from Nordic countries. ${ }^{34}$

Additionally, host genes are also important in determining how well people respond to vaccination, and variation in the genes encoding our immune system accounts for much of this vaccine response heterogeneity. Studies of heritability of the pattern of response to several vaccines (for hepatitis B, oral polio, tetanus, and diphtheria) have suggested that significant genetic contributions ${ }^{35-37}$ and variation in response, including adverse effects to HPV vaccine, is no less likely to be heritable. To date, little or no research has been conducted on host genetic factors involved in failure or variability of the response to HPV vaccine, primarily because of high antibody titer response in the short duration of follow-up studies, and the long-term differential response and effects are yet to be determined.

\section{Current recommendations for vaccination and screening}

The 2011 recommended childhood and adolescent immunization schedules were approved by the Advisory Committee of Immunization Practices (ACIP), American Academy of Pediatrics, and the American Academy of Family Physicians, which are the primary US vaccination councils, and are summarized in Table 3. Both Gardasil and Cervarix are recommended for prevention of precancerous and cancerous cervical lesions, and females aged 11-12 years are the targeted vaccination age group, but can be administered to females as young as 9 years. These guidelines were updated in 2009 to include permissive vaccination in males with Gardasil for genital warts. ${ }^{38}$ Because screening before the age of 21 years was found to have little or no impact on the incidence of cervical cancer, ${ }^{39}$ in June 2009, representatives from the American College of Obstetricians and Gynecologists and approximately 25 other organizations revised their guidelines to delay cervical cancer screening until age 21 years. ${ }^{40}$

\section{Cost-effectiveness of vaccine}

Through Papanicolaou (Pap) test screening, the rates of cervical cancer have decreased by $70 \%$ over the past 50 years. However, the rates of cervical cancer are still high worldwide. ${ }^{41,42}$ Many of the women who are diagnosed with cervical cancer are either not being treated or are not routinely undergoing screening. The low sensitivity of the Pap test $(60 \%-70 \%)^{43}$ would result in high false-positive rates, so women would be receiving costly additional tests, compounded by the high emotional burden of dealing with these potential precancerous lesions. ${ }^{44}$ Approximately 55 million Pap tests are performed each year in the USA on adult women, and, of these, about 3.5 million (6\%) find abnormal results that require medical follow-up. ${ }^{45}$ Total direct medical costs associated with cervical cancer prevention and treatments in the USA are estimated to be at least $\$ 4$ billion per year. ${ }^{46}$ While the Pap test has been an effective way to keep cervical cancer rates low in the USA, it is not cost-effective, so implementation of the HPV vaccine seems to be a viable alternative. The HPV vaccine could reduce the total direct and indirect costs by preventing primary infection and the development of precancerous lesions and cancers. ${ }^{47}$ Armstrong ${ }^{47}$ and Techakehakij and Feldman ${ }^{48}$ recently summarized several models implemented to assess cost-effectiveness of the HPV vaccine. Assuming 90\%-100\% vaccine efficacy, at least $70 \%$ vaccine coverage, and either 10 -year or lifetime protection, ${ }^{47}$ these studies in general have shown a range of incremental cost-effectiveness ratios for the HPV vaccine between $\$ 16,000$ and \$27,231 (median \$25,400) per quality-adjusted life year gained from preventing HPV genotypes 16 and $18 .{ }^{48}$ There seems to be consistent positive quality-adjusted life year findings across models, provided sufficient duration of protection, clearly suggesting that routine HPV vaccination of adolescents is cost-effective.

Men also have HPV-related diseases and can transmit the virus to both men and women through sexual activity. 
Table 3 US HPV vaccine licensure and recommended schedules $23,83,102-105$

\begin{tabular}{|c|c|c|c|}
\hline & \multirow{2}{*}{$\begin{array}{l}\text { Cervarix }{ }^{\circledR} \text { HPV types } 16 \text { and } 18 \\
\text { Females }\end{array}$} & \multicolumn{2}{|c|}{ Gardasil $^{\circledR} \mathrm{HPV}$ types $6,11,16$, and 18} \\
\hline & & & Males \\
\hline $\begin{array}{l}\text { FDA licensure and } \\
\text { usage for vaccination }\end{array}$ & $\begin{array}{l}\text { Age I0-25 years for: } \\
\text { - Cervical cancer } \\
\text { - CIN Grades } 2 \text { or } \\
\text { worse and AIS } \\
\text { - CIN Grade I }\end{array}$ & $\begin{array}{l}\text { Age 9-26 years for: } \\
\text { - Cervical cancer } \\
\text { - CIN Grade I, CIN Grade } 2 \\
\text { or worse and AIS } \\
\text { - Condylomata acuminata } \\
\text { - VIN grade } 2 \text { and grade } 3 \\
\text { - VaIN grade } 2 \text { and grade } 3 \\
\text { - Anal precancerous lesions } \\
\text { and cancer (HPV types 6, II, } \\
\text { 16, and 18) }\end{array}$ & $\begin{array}{l}\text { Age 9-26 years for: } \\
\text { - Genital warts (HPV types } 6 \text { and II) } \\
\text { - Anal cancer and associated } \\
\text { precancerous lesions (HPV types } \\
\text { 6, II, 16, and I8) } \\
\text { - CIN Grades } 2 \text { or worse and AIS } \\
\text { - CIN Grade I }\end{array}$ \\
\hline \multirow[t]{5}{*}{ ACIP guidelines } & & $\begin{array}{l}\text { For prevention of cervical } \\
\text { cancers, precancers, and } \\
\text { genital warts }\end{array}$ & $\begin{array}{l}\text { May be administered to reduce the } \\
\text { likelihood of genital warts }\end{array}$ \\
\hline & \multicolumn{3}{|c|}{ - Either vaccine is recommended for the prevention of cervical precancers, cancers, and genital warts } \\
\hline & \multicolumn{3}{|c|}{ - Females as young as 9 years eligible } \\
\hline & \multicolumn{3}{|c|}{ - Females aged II-12 for routine HPV vaccination } \\
\hline & \multicolumn{3}{|c|}{ - Females aged I3-18 for catch up vaccination } \\
\hline Dosing & \multicolumn{3}{|c|}{$\begin{array}{l}\text { A complete series is three doses; the second dose should be administered I-2 months after the first dose; the third dose } \\
\text { should be administered } 6 \text { months after the first dose }\end{array}$} \\
\hline Cost & \multicolumn{3}{|c|}{ Approximately $\$ 384$ (approximately $\$ 184$ per dose $\times$ three doses) } \\
\hline Special situations & \multicolumn{3}{|c|}{$\begin{array}{l}\text { - Can be administered to females who have abnormalities on their cervical cancer screening or to those with active or } \\
\text { past history of genital warts; vaccine can protect against infection with HPV vaccine types not already acquired. } \\
\text { - Prevaccination assessments such as Papanicolau testing, screening for high-risk HPV DNA, or serologic testing are } \\
\text { not indicated. } \\
\text { - Safe in lactating women }\end{array}$} \\
\hline $\begin{array}{l}\text { Immunocompromised } \\
\text { individuals }\end{array}$ & \multicolumn{3}{|c|}{$\begin{array}{l}\text { Vaccines can be administered to individuals who are immunosuppressed from disease or medications, but the immune } \\
\text { response and vaccine efficacy may be less than that in immunocompetent individuals }\end{array}$} \\
\hline Not recommended & \multicolumn{3}{|c|}{ Pregnant women and women above the age of 26 years } \\
\hline
\end{tabular}

Note: Information based on multiple resources. . $3,83,102-105^{2}$

Abbreviations: ACIP, Advisory Committee of Immunization Practices; FDA, US Food and Drug Administration; HPV, human papillomavirus; AIS, cervical adenocarcinoma in situ; CIN, cervical intraepithelial neoplasia; VIN, vulvar intraepithelial neoplasia; VaIN, vaginal intraepithelial neoplasia.

HPV infection rates have been reported to be similar between males and females. ${ }^{29}$ Several studies have reported that the probability of new genital HPV infection among sexually active males within a 12-month period ranges from $0.29-0.39$ per 1000 person-months, similar to those in females. ${ }^{49-51}$ Dunne et al indicated that the prevalence and incidence of HPV are generally similar but vary based on the populations and methodology used to detect infection. ${ }^{52}$ Given that males can be carriers of HPV, vaccinating them would not only prevent infection in them individually but would increase "herd immunity." Herd immunity can be achieved only by acceptance and involvement of both genders rather than narrowly targeted populations. ${ }^{53}$ However, vaccination of males has produced mixed cost-effectiveness results. ${ }^{47}$ Several studies reported a gain in incremental cost-effectiveness ratios, ${ }^{54,55}$ while others reported no gain in cost-effectiveness. ${ }^{56}$ Brisson et al reported male vaccination to be cost-effective when the vaccination rates of young women are low (below 50\%), but not when they are high (above 70\%). ${ }^{57}$ Currently, vaccination rates among young women are lower than the expected $70 \%$, based on assumptions in the cost-effectiveness model. ${ }^{47}$ Therefore, it seems more cost-effective to vaccinate both young males and females under the assumptions made. However, due to the uncertainty in these cost-effective models for males, the ACIP recommended permissive use of the HPV vaccine in males. ${ }^{38}$ Likewise, the cost-effectiveness of HPV vaccination in adult women is also uncertain.

\section{Uptake}

Since 2006, when the Gardasil vaccine was licensed in the USA, approximately 33 million doses have been distributed in the USA. ${ }^{58}$ In $2009,17.1 \%$ of women aged $19-26$ years in the USA had received at least one dose of the HPV vaccine, an increase of over $10.5 \%$ in $2008 .{ }^{59}$ In adolescent females aged 13-17 years, approximately $44.3 \%$ had received at least one dose of the HPV vaccine, and $26.7 \%$ had received all three doses of the vaccine in the USA in $2009 .{ }^{60}$ For the first dose of HPV vaccine in adolescents, race/ethnicity seems to make no difference in coverage (Figure 2). However, compared with those living at or above the poverty level, 


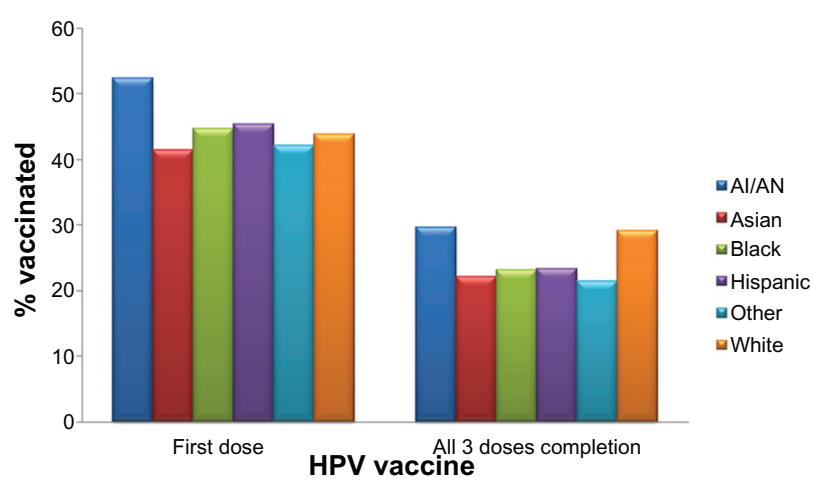

Figure 2 HPV vaccine coverage (in percent) for 13-17-year-old adolescents by race/ethnicity for at least one dose and for complete three doses. The percent coverage is based on data on either Gardasil $^{\circledR}$ or Cervarix ${ }^{\circledast}$ vaccine among 9621 females. Persons who identified as Native Hawaiian or other Pacific Islanders and persons of multiple races were categorized as other.

Notes: Excerpted from the 2009 National Immunization Survey-Teen. ${ }^{60,98}$ Adapted from Centers for Disease Control and Prevention. National, state, and local area vaccination coverage among adolescents aged 13-17 years - United States, 2009. MMWR 2010;59:1018-1023 and Centers for Disease Control and Prevention. 2009 NIS-Teen Vaccination Coverage Table Data; 2011.

Abbreviations: HPV, human papillomavirus; Al, American Indian; AN, Alaskan Natives.

HPV vaccine initiation is higher among those living below the poverty level (42.5\% versus $51.9 \%) .{ }^{60}$ Coverage with three doses in adolescents was lower among African Americans (23.1\%) and Latinos (23.4\%) compared with Caucasians (29.3\%), as shown in Figure 2. ${ }^{60}$

As seen in Figure $3 \mathrm{~A}$ and $3 \mathrm{~B}$, HPV vaccine uptake in adolescent females differs geographically. ${ }^{60}$ In general, the Northeast and Midwest regions have the highest rates of HPV vaccination initiation (Figure 3A) in the USA, while the Southeast has the lowest rates of vaccine initiation. HPV vaccine completion rates (three doses) are significantly lower for the majority of states, except in South Dakota and several Northeastern states (Figure 3B). Of note, it is interesting that states such as Alabama, Louisiana, and California have a high initiation of HPV vaccine compared with other states but have very low vaccine completion (Figure $3 \mathrm{~A}$ and B). States with the highest rates of cervical cancer mortality include Mississippi, Arkansas, West Virginia, Tennessee, Texas, and Alabama, which are predominantly in the South/ Southeast, and states with the lowest rates of cervical cancer mortality include Massachusetts, Connecticut, Minnesota, North Dakota, and Rhode island, which are in the Northeast and Midwest. ${ }^{61,62}$ In general, the states with the highest rates of cervical cancer mortality seem to have the lowest vaccine coverage, while the states with the lowest rates of cervical cancer mortality have the highest vaccine coverage.

Post-licensure HPV male vaccination rates have not been published, because the vaccine licensure and recommendations were not extended to males until 2009. Vaccination of males is important, both because rates of HPV vaccination in females is currently lower than anticipated, and for the reasons discussed above, for achieving herd immunity. Vaccinating only females leaves men who have sex with men (MSM) an extremely at-risk group for HPV-associated malignancies, unprotected. MSM and men who have sex with men and women are more likely to be infected with genital, anal, or oral HPV than men who have sex only with women. ${ }^{51,63,64}$ The rates of anal cancer in high-risk groups such as MSM are comparable with cervical cancer rates prior to routine screening, and these rates are even higher among human immunodeficiency virus (HIV)-positive MSMs. ${ }^{65,66}$ Additionally,
A

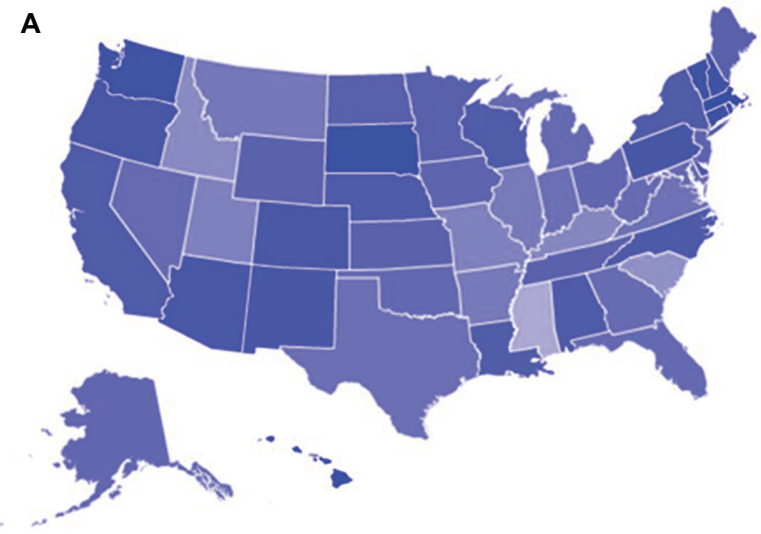

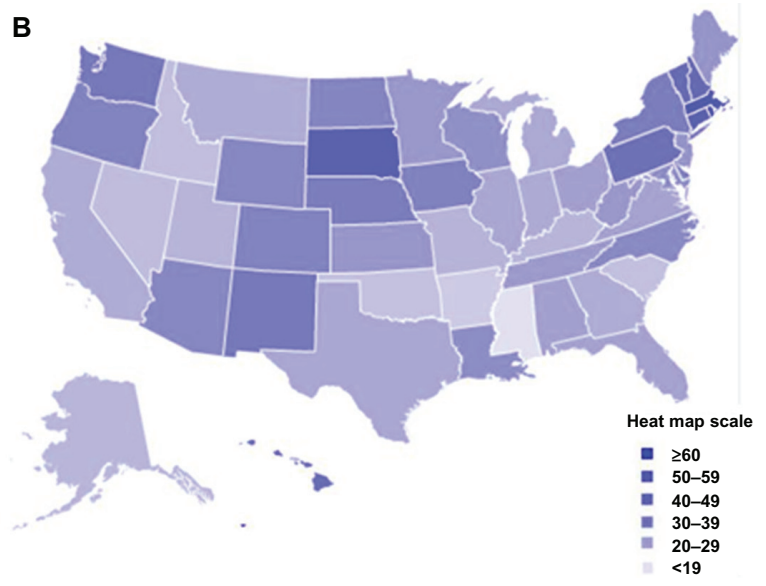

B

Figure 3 HPV vaccination uptake in 13-17-year-old adolescents by state in the USA. Estimated percent coverage for (A) first dose of the HPV vaccine and (B) all three doses of the HPV vaccine.

Notes: Based on data excerpted from the 2009 National Immunization Survey-Teen. ${ }^{60,98}$ Adapted from Centers for Disease Control and Prevention. National, state, and local area vaccination coverage among adolescents aged 13-17 years - United States, 2009. MMWR 2010;59:1018-1023 and Centers for Disease Control and Prevention. 2009 NIS-Teen Vaccination Coverage Table Data; 201 I.

Abbreviation: HPV, human papilloma virus. 
the prevalence of vaccine type HPV infection is high among MSM and men who have sex with men and women; thus, vaccinating this population is very logical. Kim reported that HPV vaccination of MSM may be cost-effective to prevent anal cancer and genital warts, with about $\$ 37,830$ per quality-adjusted life year gained under the best case scenario. ${ }^{67}$ Additional convincing cost-effectiveness data, preferably above the minimum benchmark of $\$ 50,000$, would be required for the ACIP to recommend routine vaccination in this group. Further, targeting this population before sexual onset is difficult due to social stigmatization and unknown sexual orientation, specifically at an early age.

\section{Uptake and recommendations in special populations HIV population}

In 2004 in the USA, there were 4883 HIV diagnoses in the age group 13-24 years, which represents $13 \%$ of the total new cases of HIV infection. ${ }^{68} \mathrm{HPV}$-associated cancers occur frequently in HIV patients with acquired immunodeficiency syndrome (AIDS). ${ }^{69}$ Thus, in 1993, the Centers for Disease Control (CDC) added cervical cancer as an AIDSdefining condition. ${ }^{70}$ In the AIDS Malignancy Consortium Protocol 052, ${ }^{71}$ no adverse events, including in CD4 count and HIV RNA levels, were attributable to quadrivalent HPV vaccination among the $109 \mathrm{HIV}$-positive men who received at least one dose of vaccine. Seroconversion was observed (98\%-100\%) for all four types. Results for trials in children aged 7-12 years have shown similar results. ${ }^{72}$ However, results from efficacy trials are not yet available to make any recommendations.

\section{Pregnant women}

In the USA, approximately 900,000 teenagers become pregnant each year. ${ }^{73}$ While the HPV vaccine did not appear to affect pregnancy outcomes in Phase III clinical trials negatively, the HPV vaccine has not been approved for pregnant women. ${ }^{74}$ Additional trials and observations are being conducted to make the recommendations.

\section{Organ transplant patients}

Each year in the USA, there are about 2591 transplant candidates younger than 18 years, and about 1892 undergo transplantation. ${ }^{75}$ Women undergoing organ and bone marrow transplantation tend to be at increased risk for HPV-related genital and oral disease, including cancer. ${ }^{76-78}$ It seems these patients are also very vulnerable to HPV and infection outcomes. Vaccine trials are underway to assess HPV vaccine efficacy and adverse effects in this vulnerable population, but to date no specific recommendations have been made.

\section{Survivors of childhood cancer}

Women surviving childhood cancer are at increased risk of second malignancies. Nevertheless, the relationship between childhood cancer and HPV-related cancer is not known and has not been consistently observed. While the median age for cervical cancer is $47-48$ years, most of the female survivors in the Childhood Cancer Survivor Study cohort are currently too young to assess for HPV-related complications. However, females receiving specific types of cancer therapy during childhood tend to be vulnerable to HPV-related diseases. ${ }^{79}$ Ongoing studies are examining vaccination in the childhood cancer survivor population. However, the Children's Oncology Group's Long-Term Follow-Up Guidelines for Survivors of Childhood, Adolescent, and Young Adult Cancer (version 3.0) recommend HPV vaccination for all eligible females surviving childhood cancer.

\section{Barriers and challenges to vaccination}

Current recommendations for the HPV vaccine require a three-dose series, and it is evident from the National Immunization Survey-Teen conducted by the CDC in 2009 that adolescents are not receiving all three doses $(44.3 \%$ had one dose and $26.7 \%$ had all three doses) ${ }^{60}$ In a large study of 3297 females, Widdice et al reported low overall completion rates, ie, $21.4 \%$ in $9-10$-year-olds, $19.6 \%$ in 11-12-year-olds, $29.6 \%$ in 13-18-year-olds, and $30.4 \%$ in 9-26-year-olds. ${ }^{80}$ Currently, race does not seem to make a difference as to whether one receives the first dose of the HPV vaccine. However, African American women tend to have lower rates of three-dose completion than Caucasian females aged 9-26 years. ${ }^{80,81}$ If racial disparities do exist in vaccine completion rates, this could intensify existing disparities in cervical cancer. One study suggested that vaccine completion in adolescent females also depended on the reasons for clinical visits; higher vaccine completion was observed among those who had a vaccine-only visit versus a nonsick or sick visit. ${ }^{82}$ This indicates that providing vaccine-specific visits to the clinic along with reminders could increase the uptake.

One of the issues regarding adherence to the vaccine schedule, or even starting the HPV vaccine process, is the cost of the vaccine. The cost for a single dose of the HPV vaccine is approximately $\$ 130 .{ }^{83}$ Most health insurance plans cover recommended vaccines such as HPV for the recommended age group. However, the cost is high if it is 
not covered, especially if it comes as an unexpected medical bill. In the National Immunization Survey-Teen, the majority of adolescents (49\%) had insurance, 34\% were covered under Vaccines for Children, and 17\% were either underinsured or not qualified for Federally Qualified Health Centers (Figure 4). ${ }^{60}$ Vaccines for Children is a federally funded program that helps eligible children (those on Medicaid, uninsured, American Indian or Alaskan Native, or underinsured) receive necessary vaccines. ${ }^{84}$ Adolescent females with private insurance were more likely to complete the HPV vaccine series than those with Medicaid. ${ }^{82}$ As of January 2011, adolescent males were also eligible for the Vaccines for Children to assist with permissive use of HPV vaccine, as recommended by the ACIP. ${ }^{85}$ Prior to government assistance, it is possible that vaccination rates in males remained low, and now through Vaccines for Children, vaccination rates in males are expected to increase. However, vaccination rates for males are unlikely to be as high as for females because the vaccine is still recommended only for "permissive use" in males. Even with such encouraging programs to help cover the costs of HPV vaccine, several issues need to be carefully monitored and considered to encourage uptake of the vaccine in adolescent males and females.

\section{Parents}

Parent's perception of the HPV vaccine plays a vital role regarding adherence to and administration of the vaccine. Parents have been found to be influenced by: denial of risk, believing that their child is not currently at risk for HPV because she/he is not sexually active and want to wait until they become sexually active; ${ }^{45}$ concerns about vaccine safety, feeling the vaccine is "too new" because the HPV vaccine was approved by the FDA less than 10 years ago, and some did not feel they knew enough about the long-term side effects; ${ }^{86}$
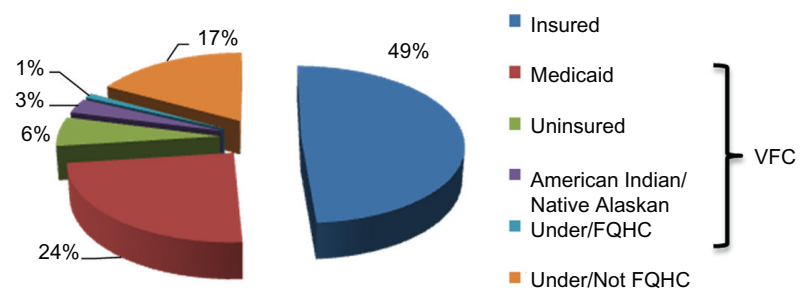

Figure 4 Financial sources among adolescents receiving HPV vaccine. Vaccine is mostly covered by individual insurance, Vaccine for Children (VFC) program (those on Medicaid, uninsured, American Indian or Alaskan Native or underinsured), and Federally Qualified Health Centers.

Notes: Based on data excerpted from the 2009 National Immunization Survey-Teen; ${ }^{99}$ adapted from Centers for Disease Control and Prevention. National, state, and local area vaccination coverage among adolescent aged 13-17 years - United States, 2008. MMWR Morb Mortal Wkly Rep. 2009;58(36):997-100I. Data are presented as percentages.

Abbreviation: HPV, human papillomavirus. riskier adolescent behaviors, feeling that an STI vaccine could promote sexual promiscuity because the adolescent would feel less at-risk; ${ }^{87,88}$ reluctance regarding STI immunization and a sexuality discussion with the child, having a difficult time discussing sex with their child, and early childhood vaccination would bring up sex for discussion; ${ }^{89}$ belief that the child receives too many vaccines, with anxiety about vaccine side effects and the health of their children as a result; ${ }^{88}$ and concern that health insurance will not cover the vaccine and they will be left with the "unnecessary" bill. ${ }^{86}$ The majority of the concerns parents have can be avoided with proper education regarding the HPV vaccine. Knowledge of the benefits of the HPV vaccine could help enlighten parents and assist them in making an informed decision. Parent sociodemographic variables, such as ethnicity and religion, are also strongly associated with acceptance of the HPV vaccine. ${ }^{90} \mathrm{HPV}$ awareness is lower among ethnic minority women than among Caucasian women and lower among non-Christian than Christian mothers. ${ }^{90}$ In a multinational review of parental attitudes about HPV vaccination, there was little difference between parental attitudes about vaccinating their daughters $(70 \%)$ versus their sons $(65 \%))^{20,91}$ The main reason parents refused to vaccinate their sons was that they did not believe their child would benefit directly from the HPV vaccine..$^{20}$

\section{Health care providers}

Physicians' and health care providers' recommendations for the HPV vaccine are likely to influence parents' and adolescents' decisions regarding vaccination. A physician's attitude toward vaccination has been shown to be influenced by professional characteristics, office procedures, and vaccine cost and reimbursement. ${ }^{45}$ Physicians and parents prefer the vaccination of older adolescent males and females, ${ }^{20,86,92}$ leaving out the most vulnerable and recommended younger adolescents. This is likely due to the HPV vaccine being a STI vaccine, because parents and physicians possibly feel older adolescents have a greater need for the vaccine. When it comes to choosing a vaccine for males, physicians in general prefer a vaccine that protects against both genital warts and cervical cancer as opposed to a vaccine that is known to protect only against cervical cancer. ${ }^{20}$

\section{Vaccinees}

HPV vaccine acceptance is also dependent on adolescents' opinions of the vaccine. Adolescents' knowledge of HPV appears to be influenced by physicians and health educators, peer groups, and media. ${ }^{45}$ Adolescents' acceptance of 
STI vaccines is generally high and has been found to be influenced positively by perception of vaccine characteristics, health benefits, provider recommendations, increased perceived susceptibility to STIs, and perceived benefit of immunization. On the other hand, adolescents' negative reactions are due mostly to vaccine causing infection, low perception of risk, and fear of needles. ${ }^{45}$ Adolescents' acceptance of the vaccine is high, but the actual rates of initiation and completion of the HPV vaccine are low. In a study of college-aged males, 34\% would accept a vaccine that protected against cervical cancer alone, while $78 \%$ would accept a vaccine that protected against both cervical cancer and genital warts. ${ }^{93}$ Again, there is greater acceptance of male vaccination when there is a direct benefit to the person being vaccinated.

\section{Safety}

The safety of both HPV vaccines is continually monitored by the $\mathrm{CDC}$ and the FDA via three reporting systems that can track adverse events known to be associated with vaccines as well as detect rare adverse events that may not have been identified by the relevant clinical trials. Safety information based on clinical trials for both vaccines is listed in Table 2. Post-licensing safety information from the Vaccine Adverse Event Reporting System reported that, as of February 14, 2011 , there have been a total of 18,354 adverse events following Gardasil vaccination and 26 adverse event reports following Cervarix vaccination in the USA. ${ }^{58}$ Since the FDA licensure of Gardasil for males in 2009, there have been 205 Vaccine Adverse Event Reporting System reports, of which 15 were serious adverse events. ${ }^{58}$ The vast majority of these reports in females were considered nonserious (92\% for Gardasil and $96 \%$ for Cervarix), defined by the Vaccine Adverse Event Reporting System as adverse events other than hospitalization, death, permanent disability, or lifethreatening illness. ${ }^{58}$

\section{School}

Successful vaccine programs require vaccination for school entry, ensuring that all students are protected before entering school. However, HPV vaccine will not be required for middle-school entry in any state anytime in the near future. ${ }^{94}$ The state mandates for HPV vaccine are discussed among legislators each year and have failed to pass thus far. For example, Texas governor, Rick Perry, issued an executive order in early February 2007 requiring HPV vaccine for girls upon entry into middle school. ${ }^{94}$ However, controversial political agendas overruled, overshadowing the public health benefit. In New Hampshire and South Dakota, while the vaccine was not mandated, the governors provide the vaccine at no cost to girls under 18 years. ${ }^{94}$ Likewise, Washington's legislature approved spending $\$ 10$ million to vaccinate 94,000 girls voluntarily in the next 2 years. ${ }^{94}$ As indicated in Figure $3 \mathrm{~A}$ and $3 \mathrm{~B}$, the uptake of the HPV vaccine is more evident in such states where cost is subsidized or minimized by the government. While mandatory vaccination for children in each state allows parents to opt out of vaccine requirements due to medical, moral, or religious opposition, ${ }^{95}$ only $11 \%$ of Caucasian parents supported HPV vaccine mandates compared with $78 \%$ of African-American parents and $90 \%$ of Latino parents. ${ }^{96}$

\section{Conclusion}

Although Gardasil and Cervarix are effective against selected HPV infections and associated cervical precancers, there are several challenges to the delivery and uptake of the vaccine. Both vaccines are prophylactic and do not eliminate existing infections, so regular Pap screening is still necessary for the care and treatment of those already infected. Also the vaccines do not cover all HPV types, and currently, cross-strain protection against other oncogenic strains has not been shown. Total longevity of protection against HPV from the vaccine is not known. However, to date, immunogenicity has been sustained for up to 6.4 years. This follow-up time is not adequate to assess the effect on cancer because it takes 20-25 years to develop the disease. In addition, uptake of the vaccines is challenged by the high cost, feasibility, and logistics of three dose deliveries. The biggest impact on acceptability of the vaccine comes from adolescents, physicians, parents, and the community. Disparity in HPV vaccine uptake also exists by geographical area, income status, risk of cervical cancer, and HPV-related malignancies, gender, and race, as evident from the national study in the USA. Until these shortcomings are addressed and everyone from parents and physicians to community leaders are involved in the program, vaccine uptake efforts cannot be fully successful, especially in adolescents. New methods and technology that might involve adolescents regularly, including social networking websites, text-messaging, e-mails and other Web-based tools should be considered and utilized to educate and increase the uptake of HPV vaccine. HPV uptake and availability globally are beyond the scope of this review, but the challenges and issues should be carefully compared with those observed in the USA to assess and implement optimal uptake among the most vulnerable individuals around the world. 


\section{Disclosure}

The authors report no conflicts of interest in this work.

\section{References}

1. Bosch FX, Manos MM, Munoz N, et al. Prevalence of human papillomavirus in cervical cancer: a worldwide perspective. International biological study on cervical cancer (IBSCC) Study Group. J Natl Cancer Inst. 1995;87(11):796-802.

2. Marcell A. Adolescence. In: Kliegman RM, Behrman RE, Jenson HB, Stanton BF, editors. Nelson Textbook of Pediatrics. 18th ed. Philadelphia, PA: Saunders Elsevier; 2007.

3. Winer RL, Lee SK, Hughes JP, et al. Genital human papillomavirus infection: incidence and risk factors in a cohort of female university students. Am J Epidemiol. 2003;157(3):218-226.

4. Abma JC, Martinez GM, Mosher WD, Dawson BS. Teenagers in the United States: sexual activity, contraceptive use, and childbearing, 2002. National Center for Health Statistics. Vital Health Stat. 2004; 23(24):1-48.

5. Eaton DK, Kann L, Kinchen S, et al. Youth risk behavior surveillance - United States, 2005. Morb Mortal Wkly Rep Surveill Summ. 2006;55(5):1-108.

6. Weinstock H, Berman S, Cates W Jr. Sexually transmitted diseases among American youth: incidence and prevalence estimates, 2000. Perspect Sex Reprod Health. 2004;36(1):6-10.

7. Bartholomew DA. Human papillomavirus infection in adolescents: a rational approach. Adolesc Med Clin. 2004;15(3):569-595.

8. Fisher M, Rosenfeld WD, Burk RD. Cervicovaginal human papillomavirus infection in suburban adolescents and young adults. $J$ Pediatr. 1991;119(5):821-825.

9. Moscicki AB, Palefsky J, Gonzales J, Schoolnik GK. Human papillomavirus infection in sexually active adolescent females: prevalence and risk factors. Pediatr Res. 1990;28(5):507-513.

10. Ferreccio C, Prado RB, Luzoro AV, et al. Population-based prevalence and age distribution of human papillomavirus among women in Santiago, Chile. Cancer Epidemiol Biomarkers Prev. 2004; 13(12):2271-2276.

11. Sherman ME, Schiffman M, Cox JT. Effects of age and human papilloma viral load on colposcopy triage: data from the randomized Atypical Squamous Cells of Undetermined Significance/Low-Grade Squamous Intraepithelial Lesion Triage Study (ALTS). J Natl Cancer Inst. 2002;94(2):102-107.

12. Brown DR, Shew ML, Qadadri B, et al. A longitudinal study of genital human papillomavirus infection in a cohort of closely followed adolescent women. J Infect Dis. 2005;191(2):182-192.

13. Moscicki AB. Genital HPV infections in children and adolescents. Obstet Gynecol Clin North Am. 1996;23(3):675-697.

14. Stanley M. HPV - immune response to infection and vaccination. Infect Agent Cancer. 2010;5:19.

15. Walboomers JM, Jacobs MV, Manos MM, et al. Human papillomavirus is a necessary cause of invasive cervical cancer worldwide. $J$ Pathol. 1999;189(1):12-19.

16. Schiffman MH, Castle P. Epidemiologic studies of a necessary causal risk factor: human papillomavirus infection and cervical neoplasia. J Natl Cancer Inst. 2003;95(6):E2.

17. Bosch FX, Lorincz A, Munoz N, Meijer CJ, Shah KV. The causal relation between human papillomavirus and cervical cancer. J Clin Pathol. 2002;55(4):244-265.

18. Bosch FX. Epidemiology of human papillomavirus infections: new options for cervical cancer prevention. Salud Publica Mex. 2003;45 Suppl :S326-S339. Spanish.

19. Bosch FX, de Sanjose S. Human papillomavirus in cervical cancer. Curr Oncol Rep. 2002;4(2):175-183.

20. Liddon N, Hood J, Wynn BA, Markowitz LE. Acceptability of human papillomavirus vaccine for males: a review of the literature. $J$ Adolesc Health. 2010;46(2):113-123.
21. Kjaer SK, Tran TN, Sparen P, et al. The burden of genital warts: A study of nearly 70,000 women from the general female population in the 4 Nordic countries. J Infect Dis. 2007;196(10):1447-1454.

22. Pallecaros A, Vonau B. Human papilloma virus vaccine - more than a vaccine. Curr Opin Obstet Gynecol. 2007;19(6):541-546.

23. US Food and Drug Administration. Approval letter: human papillomavirus quadrivalent (types $6,11,16,18$ ) vaccine, recombinant; June 8, 2006. Available from: http://www.fda.gov/BiologicsBloodVaccines/Vaccines/ApprovedProducts/ucm111283.htm. Accessed May 28, 2011.

24. US Food and Drug Administration. FDA approves new vaccine for prevention of cervical cancer; October 16, 2009. Available from: http://www.fda.gov/NewsEvents/Newsroom/PressAnnouncements/ ucm187048.htm. Accessed February 16, 2011.

25. US Prescribing Information for GARDASIL ${ }^{\circledR}$ updated; Indication not granted for use in adult women; April 6, 2011. Available from: http://www.merck.com/newsroom/news-release-archive/vaccinenews/2011_0406.html. Accessed May 28, 2011.

26. Garland SM, Hernandez-Avila M, Wheeler CM, et al. Quadrivalent vaccine against human papillomavirus to prevent anogenital diseases. N Engl J Med. 2007;356(19):1928-1943.

27. Paavonen J, Naud P, Salmeron J, et al. Efficacy of human papillomavirus (HPV)-16/18 AS04-adjuvanted vaccine against cervical infection and precancer caused by oncogenic HPV types (PATRICIA): final analysis of a double-blind, randomised study in young women. Lancet. 2009;374(9686):301-314.

28. Romanowski B, de Borba PC, Naud PS, et al. Sustained efficacy and immunogenicity of the human papillomavirus (HPV)-16/18 AS04adjuvanted vaccine: analysis of a randomised placebo-controlled trial up to 6.4 years. Lancet. 2009;374(9706):1975-1985.

29. Giuliano AR, Palefsky JM, Goldstone S, et al. Efficacy of quadrivalent HPV vaccine against HPV infection and disease in males. $N$ Engl $J$ Med. 2011;364(5):401-411.

30. US Food and Drug Administration. FDA approves new indication for gardasil to prevent genital warts in men and boys; October 16, 2009. Available from: http://www.fda.gov/NewsEvents/Newsroom/PressAnnouncements/ucm187003.htm. Accessed May 28, 2011.

31. Villa LL, Ault KA, Giuliano AR, et al. Immunologic responses following administration of a vaccine targeting human papillomavirus Types 6 , 11, 16, and 18. Vaccine. 2006;24(27-28):5571-5583.

32. Block SL, Nolan T, Sattler C, et al. Comparison of the immunogenicity and reactogenicity of a prophylactic quadrivalent human papillomavirus (types 6, 11, 16, and 18) $\mathrm{L} 1$ virus-like particle vaccine in male and female adolescents and young adult women. Pediatrics. 2006;118(5): 2135-2145

33. Koutsky L. Epidemiology of genital human papillomavirus infection. Am J Med. 1997;102(5A):3-8.

34. Clinicaltrials.gov. US NLoM.Identifier NCT01077856, Vaccine Impact in Population Study (VIP); 2006. Available from: http://clinicaltrials. gov/ct2/show/NCT01077856. Accessed May 30, 2011.

35. Lee YC, Newport MJ, Goetghebuer T, et al. Influence of genetic and environmental factors on the immunogenicity of Hib vaccine in Gambian twins. Vaccine. 2006;24(25):5335-5340.

36. Newport MJ, Goetghebuer T, Weiss HA, et al. Genetic regulation of immune responses to vaccines in early life. Genes Immun. 2004;5(2):122-129.

37. Newport MJ, Goetghebuer T, Marchant A. Hunting for immune response regulatory genes: vaccination studies in infant twins. Expert Rev Vaccines. 2005;4(5):739-746.

38. US Food and Drug Administration. FDA licensure of quadrivalent human papillomavirus vaccine (HPV4, Gardasil) for use in males and guidance from the Advisory Committee on Immunization Practices (ACIP). MMWR Morb Mortal Wkly Rep. 2010;59(20):630-632.

39. Barnholtz-Sloan J, Patel N, Rollison D, et al. Incidence trends of invasive cervical cancer in the United States by combined race and ethnicity. Cancer Causes Control. 2009;20(7):1129-1138. 
40. Committee on Adolescent Health Care. ACOG Committee Opinion No. 436: evaluation and management of abnormal cervical cytology and histology in adolescents. Obstet Gynecol. 2009;113(6):1422-1425.

41. Safaeian M, Solomon D, Castle PE. Cervical cancer prevention - cervical screening: science in evolution. Obstet Gynecol Clin North Am. 2007;34(4):739-760

42. United States Cancer Statistics. Department of Health and Human Services, Centers for Disease Control and Prevention Atlanta (GA), and National Cancer Institute: U S Cancer Statistics Working Group. United States Cancer Statistics: 1999-2007 Incidence and Mortality Web-based Report; 2010. Available from: http://apps.nccd.cdc.gov/ uscs/. Accessed June 21, 2011.

43. Nanda K, McCrory DC, Myers ER, et al. Accuracy of the Papanicolaou test in screening for and follow-up of cervical cytologic abnormalities: a systematic review. Ann Intern Med. 2000;132(10):810-819.

44. Adams M, Jasani B, Fiander A. Human papilloma virus (HPV) prophylactic vaccination: challenges for public health and implications for screening. Vaccine. 2007;25(16):3007-3013.

45. Gamble HL, Klosky JL, Parra GR, Randolph ME. Factors influencing familial decision-making regarding human papillomavirus vaccination. J Pediatr Psychol. 2010;35(7):704-715.

46. Insinga RP, Dasbach EJ, Elbasha EH. Assessing the annual economic burden of preventing and treating anogenital human papillomavirusrelated disease in the USA: analytic framework and review of the literature. Pharmacoeconomics. 2005;23(11):1107-1122.

47. Armstrong EP. Prophylaxis of cervical cancer and related cervical disease: a review of the cost-effectiveness of vaccination against oncogenic HPV types. J Manag Care Pharm. 2010;16(3):217-230.

48. Techakehakij W, Feldman RD. Cost-effectiveness of HPV vaccination compared with Pap smear screening on a national scale: a literature review. Vaccine. 2008;26(49):6258-6265.

49. Partridge JM, Hughes JP, Feng Q, et al. Genital human papillomavirus infection in men: incidence and risk factors in a cohort of university students. J Infect Dis. 2007;196(8):1128-1136.

50. Giuliano AR, Lu B, Nielson CM, et al. Age-specific prevalence, incidence, and duration of human papillomavirus infections in a cohort of 290 US men. J Infect Dis. 2008;198(6):827-835.

51. Giuliano AR, Lee JH, Fulp W, et al. Incidence and clearance of genital human papillomavirus infection in men (HIM): a cohort study. Lancet. 2011;377(9769):932-940.

52. Dunne EF, Nielson CM, Stone KM, Markowitz LE, Giuliano AR. Prevalence of HPV infection among men: a systematic review of the literature. J Infect Dis. 2006;194(8):1044-1057.

53. Hull SC, Caplan AL. The case for vaccinating boys against human papillomavirus. Public Health Genomics. 2009;12(5-6):362-367.

54. Taira AV, Neukermans CP, Sanders GD. Evaluating human papillomavirus vaccination programs. Emerg Infect Dis. 2004;10(11):1915-1923.

55. Elbasha EH, Dasbach EJ, Insinga RP. Model for assessing human papillomavirus vaccination strategies. Emerg Infect Dis. 2007; 13(1):28-41.

56. Kim JJ, Goldie SJ. Cost effectiveness analysis of including boys in a human papillomavirus vaccination programme in the United States. BMJ. 2009;339:b3884

57. Brisson M, Van de Velde N, Boily MC. Economic evaluation of human papillomavirus vaccination in developed countries. Public Health Genomics. 2009;12(5-6):343-351.

58. Centers for Disease Control and Prevention. Reports of health concerns following HPV vaccination; 2011. Available from: http:/www.cdc.gov/ vaccinesafety/vaccines/hpv/gardasil.html. Accessed May 19, 2011

59. Centers for Disease Control and Prevention. 2009 Adult vaccination coverage, NHIS; 2009. Available from: http://www.cdc.gov/vaccines/ stats-surv/nhis/2009-nhis.htm. Accessed June 21, 2011.

60. Centers for Disease Control and Prevention. National, state, and local area vaccination coverage among adolescents aged 13-17 years United States, 2009. MMWR Morb Mortal Wkly Rep. 2010; 59(32): 1018-1023.
61. Bach PB. Gardasil: From bench, to bedside, to blunder. Lancet. 2010;375(9719):963-964.

62. American Cancer Society. Cancer Facts and Figures 2010. Atlanta, GA: American Cancer Society; 2010.

63. D’Souza G, Agrawal Y, Halpern J, Bodison S, Gillison ML. Oral sexual behaviors associated with prevalent oral human papillomavirus infection. J Infect Dis. 2009;199(9):1263-1269.

64. Lu B, Viscidi RP, Lee JH, et al. Human papillomavirus (HPV) 6, 11, 16 , and 18 seroprevalence is associated with sexual practice and age: results from the Multinational HPV Infection in Men study (HIM study). Cancer Epidemiol Biomarkers Prev. 2011;20(5):990-1002.

65. Palefsky JM. Human papillomavirus-related disease in men: not just a women's issue. J Adolesc Health. 2010;46(4 Suppl):S12-S19.

66. Chiao EY, Giordano TP, Palefsky JM, Tyring S, El Serag H. Screening HIV-infected individuals for anal cancer precursor lesions: a systematic review. Clin Infect Dis. 2006;43(2):223-233.

67. Kim JJ. Targeted human papillomavirus vaccination of men who have sex with men in the USA: A cost-effectiveness modelling analysis Lancet Infect Dis. 2010;10(12):845-852.

68. Centers for Disease Control and Prevention. HIV/AIDS among youth; 2008. Available from: http://www.cdc.gov/hiv/resources/factsheets/ youth.htm. Accessed May 7, 2011.

69. Frisch M, Biggar RJ, Goedert JJ. Human papillomavirus-associated cancers in patients with human immunodeficiency virus infection and acquired immunodeficiency syndrome. J Natl Cancer Inst. 2000;92(18):1500-1510

70. [No authors listed]. 1993 Revised classification system for HIV infection and expanded surveillance case definition for AIDS among adolescents and adults. MMWR Recomm Rep. 1992;41(RR-17): $1-19$.

71. Wilkin T, Lee JY, Lensing SY, et al. Safety and immunogenicity of the quadrivalent human papillomavirus vaccine in HIV-1-infected men. $J$ Infect Dis. 2010;202(8):1246-1253.

72. Levin MJ, Moscicki AB, Song LY, et al. Safety and immunogenicity of a quadrivalent human papillomavirus (types $6,11,16$, and 18) vaccine in HIV-infected children 7 to 12 years old. J Acquir Immune Defic Syndr. 2010;55(2):197-204.

73. Klein JD. Adolescent pregnancy: Current trends and issues. Pediatrics. 2005;116(1):281-286

74. Garland SM, Ault KA, Gall SA, et al. Pregnancy and infant outcomes in the clinical trials of a human papillomavirus type $6 / 11 / 16 / 18$ vaccine: a combined analysis of five randomized controlled trials. Obstet Gynecol. 2009;114(6):1179-1188.

75. Sweet SC, Wong HH, Webber SA, et al. Pediatric transplantation in the United States,1995-2004. Am J Transplant. 2006;6(5 Pt 2): 1132-1152.

76. Malouf MA, Hopkins PM, Singleton L, et al. Sexual health issues after lung transplantation: Importance of cervical screening. J Heart Lung Transplant. 2004;23(7):894-897.

77. Rose B, Wilkins D, Li W, et al. Human papillomavirus in the oral cavity of patients with and without renal transplantation. Transplantation. 2006;82(4):570-573.

78. Seshadri L, George SS, Vasudevan B, Krishna S. Cervical intraepithelial neoplasia and human papilloma virus infection in renal transplant recipients. Indian J Cancer. 2001;38(2-4):92-95.

79. Klosky JL, Gamble HL, Spunt SL, et al. Human papillomavirus vaccination in survivors of childhood cancer. Cancer. 2009;115(24):5627-5636.

80. Widdice LE, Bernstein DI, Leonard AC, Marsolo KA, Kahn JA. Adherence to the HPV vaccine dosing intervals and factors associated with completion of 3 doses. Pediatrics. 2011;127(1):77-84.

81. Stokley S. Update: HPV Vaccination Coverage Among US Adolescent Females. Presented at the Advisory Committee on Immunization Practices Meeting, Atlanta, GA, October 2010. Available from: http:// www.cdc.gov/vaccines/recs/acip/downloads/mtg-slides-oct10/08-03hpv-Female.pdf. Accessed June 21, 2011. 
82. Neubrand TP, Breitkopf CR, Rupp R, Breitkopf D, Rosenthal SL. Factors associated with completion of the human papillomavirus vaccine series. Clin Pediatr. 2009;48(9):966-969.

83. American Cancer Society. How much does the HPV vaccine cost? Is it covered by health insurance plans? 2011. Available from: http://www. cancer.org/Cancer/CancerCauses/OtherCarcinogens/InfectiousAgents/ HPV/HumanPapillomaVirusandHPVVaccinesFAQ/hpv-faq-vaccinecost. Accessed February 8, 2011.

84. Centers for Disease Control and Prevention. Vaccines for children program; 2011. Available from: http://www.cdc.gov/vaccines/ programs/vfc/default.htm. Accessed May 3, 2011.

85. Centers for Disease Control and Prevention. FDA licensure of quadrivalent human papillomavirus vaccine (HPV4, Gardasil) for use in males and guidance from the Advisory Committee on Immunization Practices (ACIP); 2010. Available from: http://www.cdc.gov/mmwr/ preview/mmwrhtml/mm5920a5.htm?s_cid = mm5920a5_e. Accessed May 2, 2011.

86. Daley MF, Crane LA, Markowitz LE, et al. Human papillomavirus vaccination practices: A survey of US physicians 18 months after licensure. Pediatrics. 2010;126(3):425-433.

87. Daley MF, Liddon N, Crane LA, et al. A national survey of pediatrician knowledge and attitudes regarding human papillomavirus vaccination. Pediatrics. 2006;118(6):2280-2289.

88. Kahn JA, Zimet GD, Bernstein DI, et al. Pediatricians' intention to administer human papillomavirus vaccine: The role of practice characteristics, knowledge, and attitudes. J Adolesc Health . 2005;37(6):502-510.

89. Kahn JA, Rosenthal SL, Tissot AM, et al. Factors influencing pediatricians' intention to recommend human papillomavirus vaccines. Ambul Pediatr. 2007;7(5):367-373.

90. Marlow LA, Wardle J, Forster AS, Waller J. Ethnic differences in human papillomavirus awareness and vaccine acceptability. J Epidemiol Community Health. 2009;63(12):1010-1015.

91. Zimet GD, Rosenthal SL. HPV vaccine and males: Issues and challenges. Gynecol Oncol. 2010;117(2 Suppl):S26-S31.

92. Dempsey AF, Abraham LM, Dalton V, Ruffin M. Understanding the reasons why mothers do or do not have their adolescent daughters vaccinated against human papillomavirus. Ann Epidemiol. 2009;19(8):531-538.

93. Jones $\mathrm{M}$, Cook R. Intent to receive an HPV vaccine among university men and women and implications for vaccine administration. J Am Coll Health. 2008;57(1):23-32.

94. National Conference of State Legislatures. HPV Vaccine: State Legislation 2009-2010; Available from: http://www.ncsl.org/ IssuesResearch/Health/HPVVaccineStateLegislation/tabid/14381/ Default.aspx. Accessed May 2, 2011.
95. Omer SB, Pan WK, Halsey NA, et al. Nonmedical exemptions to school immunization requirements: secular trends and association of state policies with pertussis incidence. JAMA. 2006;296(14):1757-1763.

96. Perkins RB, Pierre-Joseph N, Marquez C, Iloka S, Clark JA. Parents' opinions of mandatory human papillomavirus vaccination: does ethnicity matter? Womens Health Issues. 2010;20(6):420-426.

97. Parkin DM, Bray F. Chapter 2: the burden of HPV-related cancers. Vaccine. 2006;(24 Suppl 3):S11-S25.

98. Centers for Disease Control and Prevention. 2009 NIS-Teen Vaccination Coverage Table Data; 2011. Available from: http://www.cdc.gov/ vaccines/stats-surv/nisteen/data/tables_2009.htm. Accessed June 21, 2011.

99. Centers for Disease Control and Prevention. National, state, and local area vaccination coverage among adolescent aged 13-17 years - United States, 2008. MMWR Morb Mortal Wkly Rep. 2009;58(36):997-1001.

100. American Cancer Society. Global Cancer Facts and Figures 2008. Atlanta, GA: American Cancer Society; 2011.

101. World Health Organization. Human papillomavirus and related cancers in World WHO/ICO Information Centre on HPV and Cervical Cancer (HPV Information Centre); 2010. Available from: http://www.who. int/hpvcentre/en/. Accessed June 21, 2011.

102. US Food and Drug Administration. Product approval prescribing information [Package insert]. Gardasil [human papillomavirus quadrivalent (types 6, 11, 16, and 18) vaccine, recombinant]. Whitehouse Station, NJ: Merck and Co, Inc; 2009. Available from: http:/www.fda. gov/downloads/biologicsbloodvaccines/vaccines/approvedproducts/ ucm1123.pdf. Accessed May 18, 2011.

103. US Food and Drug Administration. Product approval prescribing information [package insert]. Cervarix [human papillomavirus bivalent (types 16 and 18) vaccine, recombinant]. GlaxoSmithKline Biologicals; 2009. Available from: http://www.fda.gov/biologicsbloodvaccines/vaccines/approvedproducts/ucm186957.htm. Accessed May 19, 2011.

104. Advisory Committee of Immunization Practices. National Center for Immunization and Respiratory Diseases. General recommendations on immunization. MMWR Recomm Rep. 2011;60(2):1-64.

105. US Food and Drug Administration. Approval letter: human papillomavirus bivalent (types 16,18) vaccine, recombinant; October 16, 2009. Available from: http:/www.fda.gov/BiologicsBloodVaccines/ Vaccines/ApprovedProducts/ucm186959.htm. Accessed May 8, 2011.
Adolescent Health, Medicine and Therapeutics

\section{Publish your work in this journal}

Adolescent Health, Medicine and Therapeutics is an international, peer-reviewed, open access journal focusing on health, pathology, and treatment issues specific to the adolescent age group. All aspects of health maintenance, preventative measures and disease treatment interventions are addressed within the journal and practitioners from

\section{Dovepress}

all disciplines are invited to submit their work as well as healthcare researchers and patient support groups.. The manuscript management system is completely online and includes a very quick and fair peerreview system. Visit http://www.dovepress.com/testimonials.php to read real quotes from published authors. 